\title{
Mechanisms of cell transformation induced by polyomavirus
}

M.L.S. O liveira,

S.M. Brochado and M.C. Sogayar

\section{Correspondence \\ M.C. Sogayar \\ Instituto de Q uímica, USP \\ Caixa Postal 26077 \\ 05599-970 São Paulo, SP \\ Brasil \\ Fax: +55-11-818-3820 \\ E-mail: mcsoga@ quim.iq.usp.br \\ Presented at the I International Symposium on "Signal Transduction and Gene Expression in Cell Proliferation and Differentiation", São Paulo, SP, Brasil, \\ August 31-September 2, 1998.}

Publication supported by FAPESP.

Received November 27, 1998 Accepted January 11, 1999

\section{Abstract}

Polyomavirus is a DNA tumor virus that induces a variety of tumors in mice. Its genome encodes three proteins, namely large T (LT), middle $\mathrm{T}(\mathrm{MT})$, and small T (ST) antigens, that have been implicated in cell transformation and tumorigenesis. LT is associated with cell immortalization, whereas MT plays an essential role in cell transformation by binding to and activating several cytoplasmic proteins that participate in growth factor-induced mitogenic signal transduction to the nucleus.

Key words

- Signal transduction

- Malignant transformation

- Polyomavirus T antigens

- Polyomavirus-induced transcriptional control The use of different MT mutants has led to the identification of MTbinding proteins as well as analysis of their importance during cell transformation. Studying the molecular mechanisms of cell transformation by MT has contributed to a better understanding of cell cycle regulation and growth control.

\section{Introduction}

DNA tumor viruses have proved to be important tools in the study of cell growth control and neoplasia. The relatively small size of their genomes, together with the fact that they efficiently and reproducibly induce tumors when injected in animals and with the advances in Molecular Biology techniques, has facilitated the identification and characterization of the viral proteins that are responsible for cellular transformation and tumor induction (1).

Polyomavirus (Py), a nuclear icosahedral virus containing a circular genome of doublestranded DNA, belongs to the papovavirus family and was first discovered as a tumor agent in 1953 by Ludwig Gross. Its ability to induce tumors in adult mice is relative low, but polyomavirus, as the name indicates, causes a wide variety of tumors in newborn mice (2).
Cells infected by Py express three proteins that have been implicated in cell transformation, the so-called tumor (T) antigens: large $\mathrm{T}$ (LT), middle $\mathrm{T}$ (MT) and small $\mathrm{T}$ (ST). T antigens are coded by the early region of the genome and are expressed in the early phase of the virus cycle, before replication of viral DNA. Three other proteins, namely VP1, VP2 and VP3, that are expressed after viral DNA replication, are coded by the late region of the genome and are essential for viral assembly (3).

T antigens have partially overlapping coding sequences and are generated by alternative splicing of a single RNA precursor. All $\mathrm{T}$ antigens share a common N-terminal region, but differ in the $\mathrm{C}$-terminal region as the result of a frameshift reading.

A large number of early region mutants, as well as cDNA cloning and expression of each $\mathrm{T}$ antigen, have contributed to the analysis of their role during cell transformation 
(4). Py mutants that are unable to induce tumors in animals display mutations that map in the early region of their genome.

\section{The large $T$ antigen}

The LT antigen is a $98-\mathrm{kDa}$ protein (5) that binds to specific sequences in the viral DNA, regulating both DNA replication and transcription. It acts as an important negative and positive transcriptional regulator of the early and the late regions of the genome, respectively (6-8). The amino-terminal portion of LT contains two phosphorylation sites, at tyrosine residues T187 and T278 which are potential substrates for cyclindependent kinases (CDKs). Li and colleagues (9) have reported that mutations in T278, but not in T187 abolish LT DNA replication functions. In contrast to the wild-type and T187 mutant, the T278 mutant is weakly phosphorylated by the cyclin B-cdc2 complex, suggesting the involvement of $\mathrm{S}$ and G2 phase-specific CDKs in viral replication. The importance of LT phosphorylation by this cyclin/CDK complex may explain in part why DNA tumor viruses require actively cycling host cells. Although this phosphorylation site is involved in viral DNA replication, it is not important for the ability of LT to drive cellular DNA replication (10).

LT is expressed in the nucleus of infected cells, where it binds to the product of the tumor suppressor gene $\mathrm{pRb}(11,12)$. Mutant viruses which express LT antigen defective in $\mathrm{pRb}$ binding, but normal MT antigen, are unable to immortalize primary fibroblast cultures, but are still able to transform cells established in culture $(12,13)$.

The immortality function of LT appears to be due to a block in apoptosis, even though, in contrast to SV40, polyomavirus LT does not bind the product of the tumor suppressor gene $\mathrm{p} 53$. In this case, alternative pathways may be involved (14).

In fact, Py transforms cells in culture and induces tumors in mice without an apparent interaction with or inactivation of the p53 tumor suppressor protein. Through the expression of a temperature-sensitive p53, Doherty and Freund (15) have shown that LT is able to overcome the growth suppressive activity of $\mathrm{p} 53$ despite its failure to bind $\mathrm{p} 53$, but binding to $\mathrm{pRb}$ is essential for this effect.

In Py-transformed cells, there is no significant accumulation of $\mathrm{p} 53$ protein, as opposed to SV40-transformed cells, in which the amount of steady-state p53 protein is elevated. However, accumulation of p53 is observed following exposure of Py-transformed cells to UV or X rays. Rapid induction of p21/WAF1 is also observed under these conditions, suggesting that Py does not interfere with the p53 DNA damage-induced activities (16).

\section{The small $\mathrm{T}$ antigen}

The ST antigen is a $22-\mathrm{kDa}$ protein localized in the cytoplasm of cells infected with Py, where it binds to cellular proteins such as phosphatase PP2A $(17,18)$.

Together with MT, ST appears to have a role in viral DNA synthesis, since viruses expressing mutated ST and MT show a 100fold defect in genome accumulation during infection of NIH-3T3 cells when compared to wild type viruses (19).

Although the expression of ST is not required for cell transformation, ST is able to augment the saturation density and to induce changes in the cytoskeleton (20).

\section{The middle T antigen}

The MT antigen is a 55-kDa phosphoprotein associated with the plasma membrane of cells infected with Py through a mirystyl anchor attached to the C-terminus of the protein. Its function in the viral cycle appears to be related to virus assembly, since MT induces phosphorylation of the VP1 capsid protein (21). 
Using cDNA injection in newborn mice, Asselin and colleagues (22) have shown that MT is able to induce tumors only in combination with the N-terminal region of LT and ST.

Since MT alone is able to transform cells established in culture (23), it is believed that it plays a central role during Py transformation and tumorigenesis.

The MT antigen can be phosphorylated at serine residues located in the C-terminal region of the molecule, as well as in threonine and tyrosine residues present in different regions of the protein. Its ability to transform cells is related to binding and activation of a number of cytoplasmic proteins related to cell growth control $(24,25)$. In general, the interaction between MT and cellular proteins occurs through phosphorylated tyrosine residues in MT and Src homology-2 (SH2) domains present in different signal-transducing proteins, as is the case for Src homology and collagen protein (Shc), phosphatidylinositol-3-kinase (PI3K) and phospholipase $\mathrm{C} \gamma(\mathrm{PLC} \gamma)(26,27)$. Mutations in any of these tyrosines render MT defective for transformation (24).

In addition to tyrosine-SH2 interactions, a proline-rich domain present in the MT molecule is important for binding to SH3containing proteins (27). Viruses expressing MT mutated in this proline-rich domain are partially defective for transformation and tumorigenesis and MT binding to PLC $\gamma$ is partially affected (28).

Analysis of other MT mutants has led to the identification of the $\mathrm{N}$-terminal region as the binding site for phosphatase PP2A and Src tyrosine kinase (17). Recently, MT residues 185 to 210 were reported to be essential for Src binding (29). Transformation-defective MT mutants that retain the ability to bind Src were reported, suggesting that activation of Src is not sufficient to induce transformation by MT $(24,30)$.

Cullere and colleagues (31) recently described the first MT phosphoserine residue as an important binding site for the 14-3-3 pro- tein. Mutation in MT Ser 257 completely abolishes binding, but does not affect the ability of MT to transform fibroblasts in vitro.

Activation of cellular proteins by MT triggers a variety of signals in the cell that culminate with growth proliferation, even in the absence of growth factors (32).

Thus, MT binding to She (through the $250 \mathrm{Tyr}$ residue of MT) leads to its binding to and activation of the Ras protein and, consequently, activation of the mitogen-activated protein kinase (MAPK) pathway $(33,34)$. When activated, MAPKs translocate to the nucleus, where they phosphorylate transcriptional factors, regulating the expression of genes that are essential for cell proliferation (35).

Activation of PI3K by MT occurs through association of MT Tyr 315 with the SH2 domain of the p85 regulatory subunit of PI3K (36). Elevated levels of phosphoinositides phosphorylated at position 3 of the inositol ring are observed in MT-transformed cell lines, but not in cell lines expressing the MT315 mutant (37). These molecules were reported to bind to $\mathrm{SH} 2$ domains of cellular proteins such as Src and PI3K itself, suggesting that they play a role in the regulation of these enzymes (38). Following PI3K activation by MT, induction of Akt (the protein coded by the cellular homologue of the AKT8 retrovirus oncogene) serine/threonine kinase activity is observed. Using MT mutants that are not able to bind to Shc or PI3K, Summers and colleagues (39) were able to localize Akt downstream relative to PI3K, but not to Shc. Recent studies evidenced the role of PI3K activation in the blocking of apoptosis by MT in a p53-independent manner (40).

Transgenic mice expressing MT mutants defective in binding to Shc or PI3K develop mammary epithelial hyperplasias, in contrast to rapid metastatic mammary tumors observed in strains expressing wild-type MT (41). The mammary epithelial hyperplasias expressing the MT mutant defective in recruiting PI3K are highly apoptotic, suggest- 
ing that recruitment of PI3K by MT affects cell survival. Tumor progression in both mutant strains correlates with upregulation of the epidermal growth factor receptor family members which are known to couple to the PI3K and Shc signaling pathways (41).

\section{Transcription factors in Py-MT transformation}

MT overexpressing fibroblasts display constitutively high transcription factor AP-1 activity (42) as a result of constitutive overexpression of the cJun and JunB AP-1 components (30). Induction of AP-1 activity by MT was shown to be dependent on MT binding to PI3K, but does not correlate with cell transformation, indicating that additional events are necessary (30).

Using glucocorticoid-inducible MT-overexpressing fibroblasts, Rameh and Armelin (43) have reported induction of the c-myc proto-oncogene at the mRNA level, paralleling induction of MT with glucocorticoids. Taken together, these results indicate that cMyc and Jun proteins act cooperatively during MT cell transformation.

High expression of urokinase-type plasminogen activator, which is regulated by AP- 1 consensus sequences present in its promoter, is observed in MT-transformed cell lines. Injection of MT-transformed endothelial cell lines leads to the formation of vascular tumors in newborn mice. These cell lines exhibit altered proteolytic activity that contributes to tumor growth (44).

The contribution of polyomavirus to the understanding of cell growth control and neoplasia began with the important discovery of the role played by tyrosine phosphorylation in cell proliferation (45). Since then, studies of $\mathrm{T}$ antigens have led to new findings in cell immortalization, apoptosis and transformation. In particular, MT studies have contributed to the mapping of a variety of signalling pathways related to cell growth control. Thus, expression of both wild type and mutant MT in a variety of cell types has become an important tool to understand the differences among signalling pathways in different cell systems (46).

\section{References}

1. Benjamin T \& Vogt PK (1990). Cell transformation by viruses. In: Fields BN \& Knipe DM (Editors), Virology. 2nd edn. Raven Press Ltd., New York, 317-367.

2. Kaplan DR, Pallas DC, Morgan W, Schaffhausen B \& Roberts TM (1988). Mechanisms of transformation by polyomavirus middle $T$ antigen. Biochimica et Biophysica Acta, 948: 345-364.

3. Eckhart W (1989). Oncogenes of DNA tumor viruses: papovavirus. In: Weinberg RA (Editor), Oncogenes and the Molecular Origins of Cancer. 1st edn. Cold Spring Harbor Laboratory Press, New York, 223238.

4. Markland W \& Smith AE (1987). Mutants of polyomavirus middle-T antigen. Biochimica et Biophisica Acta, 907: 299-321.

5. Ito $Y$, Brocklehurst J R \& Dulbecco $R$ (1977). Virus-specific proteins in the plasma membrane of cells lytically infected or transformed by polyoma virus. Proceedings of the National Academy of
Sciences, USA, 74: 4666-4670.

6. Farmerie W \& Folk WR (1984). Regulation of polyomavirus transcription by large tumor antigen. Proceedings of the National Academy of Sciences, USA, 81: 69196923.

7. Dailey L \& Basilico C (1985). Sequences in the polyomavirus DNA regulatory region involved in viral DNA replication and early gene expression. J oumal of Virology, 54: 739-749.

8. Kern FG, Pellegrini S, Cowie A \& Basilico C (1986). Regulation of polyomavirus late promoter activity by viral early proteins. J ournal of Virology, 1: 275-285.

9. Li H, Bhattacharyya S \& Prives C (1997). Cyclin-dependent kinase regulation of the replication functions of polyomavirus large T antigen. J ournal of Virology, 71: 64796485.

10. Chatterjee A, Bockus BJ, Gjorup OV \& Schaffhausen BS (1997). Phosphorylation sites in polyomavirus large $T$ antigen that regulate its function in viral, but not cellular, DNA synthesis. J ournal of Virology, 71: 6472-6478.

11. Dyson N, Bernards R, Friend SH, Gooding LR, Hassel J A, Major EO, Pipas JM, Vandyke T \& Harlow E (1990). Large T antigens of many polyomaviruses are able to form complexes with the retinoblastoma protein. J ournal of Virology, 64: 1353-1356.

12. Freund $\mathrm{R}$, Bronson $\mathrm{RT} \&$ Benjamin $\mathrm{TL}$ (1992). Separation of immortalization from tumor induction with polyoma large $\mathrm{T}$ mutants that fail to bind the retinoblastoma gene product. Oncogene, 7: 1979-1987.

13. Larose A, Dyson N, Sullivan M, Harlow E \& Bastin M (1991). Polyomavirus large T mutants affected in retinoblastoma protein binding are defective in immortalization. J ournal of Virology, 65: 2308-2313.

14. Zheng $D Q$, Vayssière J L, Petit $P X$, LeCoeur $\mathrm{H}$, Spatz A, Mignotte B \& Feunteun J (1994). Apoptosis is antago- 
nized by large $T$ antigens in the pathway to immortalization by polyomaviruses. Oncogene, 9: 3345-3351.

15. Doherty J \& Freund R (1997). Polyomavirus large $T$ antigen overcomes p53 dependent growth arrest. Oncogene, 14: 1923-1931.

16. Mor O, Read M \& Fried M (1997). p53 in polyoma virus transformed REF52 cells. Oncogene, 15: 3113-3119.

17. Campbell KS, Auger KR, Hemmings BA, Roberts TM \& Pallas DC (1995). Identification of regions in polyomavirus middle T and small T antigens important for association with protein phosphatase $2 \mathrm{~A}$. J ournal of Virology, 69: 3721-3728.

18. Pallas DC, Shahrik LK, Martin BL, J aspers S, Miller TB, Brautigan DL \& Roberts TM (1990). Polyoma small and middle T antigens and SV40 small T antigen form stable complexes with protein phosphatase 2A. Cell, 60: 167-176.

19. Chen MC, Redenius $D$, Osati-Ashtiani $F$ \& Fluck MM (1995). Enhancer-mediated role for polyomavirus MiddleT/Small T in DNA replication. J ournal of Virology, 69: 326333.

20. Liang TJ , Carmichael GG \& Benjamin TL (1984). A polyoma mutant that encodes small $\mathrm{T}$ antigen but not middle $\mathrm{T}$ antigen demonstrates uncoupling of cell surface and cytoskeletal changes associated with cell transformation. Molecular and Cellular Biology, 4: 2772-2783.

21. Li M \& Garcea RL (1994). Identification of the threonine phosphorylation sites on the polyomavirus major capsid protein VP1: relationship to the activity of middle T antigen. J oumal of Virology, 68: 320327.

22. Asselin C, Gelinas C \& Bastin M (1983). Role of three polyoma virus early proteins in tumorigenesis. Molecular and Cellular Biology, 3: 1451-1459.

23. Treisman R, Novak U, FavaloroJ \& Kamen $R$ (1981). Transformation of rat cells by an altered polyoma virus genome expressing only the middle T protein. Nature, 292: 595-600.

24. Armelin MCS \& Oliveira MLS (1996). Polyomavirus-induced malignant transformation: comparative analysis of wild type and mutant middle T-overexpressing cell lines. Brazilian J ournal of Medical and Biological Research, 29: 1133-1140.

25. Pallas DC, Cherington V, Morgan W, DeAnda J , Kaplan D, Schaffhausen B \& Roberts TM (1988). Cellular proteins that associate with the middle $T$ and small $T$ antigens of polyomavirus. J ournal of Virology, 62: 3934-3940.

26. Campbell KS, Ogris E, Burke B, Su W,
Auger KR, Druker BJ , Schaffhausen BS, Roberts TM \& Pallas DC (1994). Polyoma middle tumor antigen interacts with Shc protein via the NPTY (Asn-Pro-Thr-Tyr) motif in middle tumor antigen. Proceedings of the National Academy of Sciences, USA, 91: 6344-6348.

27. Su W, Liu W, Schaffhausen BS \& Roberts TM (1995). Association of polyomavirus middle tumor antigen with phospholipase C - gamma 1. J ournal of Biological Chemistry, 2705: 12331-12334.

28. Yi X \& Freund R (1998). Deletion of proline-rich domain in polyomavirus $T$ antigens results in virus partially defective in transformation and tumorigenesis. Virology, 248: 420-431.

29. Brewster CE, Glover HR \& Dilworth SM (1997). pp60c-src binding to polyomavirus middle-T antigen (MT) requires residues 185 to 210 of the MT sequence. J ournal of Virology, 71: 5512-5520.

30. Oliveira MLS, Roberts TM, Druker BJ \& Armelin MCS (1998). Mapping of polyomavirus middle $T$ domain that is responsible for AP-1 activation. Oncogene, 16: 2975-2982.

31. Cullere $X$, Rose $P$, Thathamangalam $U$, Chatterjee A, Mullane KP, Pallas DC, Benjamin TL, Roberts TM \& Schaffhausen BS (1998). Serine 257 phosphorylation regulates association of polyomavirus middle T antigen with 14-3-3 proteins. J ournal of Virology, 72: 558-563.

32. Armelin MCS, Armelin HA, Callahan MA, Cochran BH \& Stiles CD (1985). New tatics for analysis of oncogenes. In: Feramisco J , Ozanne B \& Stiles C (Editors), Cancer Cells. Cold Spring Harbor Laboratory Press, Cold Spring Harbor, 195-203.

33. Dilworth SM, Brewster CEP, J ones MD, Lanfrancone L, Pelicci G \& Pelicci PG (1994). Transformation by polyomavirus middle $T$ antigen involves the binding and tyrosine phophorylation of Shc. Nature, 367: 87-90.

34. Rozakis-Adckock M, McGlade J , M bamalu G, Pelicci G, Daly R, Li W, Batzer A, Thomas S, Brugge J , Pelicci PG, Schiessinger J \& Pawson T (1992). Association of the Shc and Grb2/Sem5 SH2-containing proteins is implicated in activation of the Ras pathway by tyrosine kinases. Nature, 360 : 689-692.

35. Hill CS \& Treisman R (1995). Transcriptional regulation by extracellular signals: mechanisms and specificity. Cell, 80: 199211.

36. Druker BJ , Ling LE, Cohen B, Roberts TM \& Schaffhausen BS (1990). A completely transformation-defective point mutant of polyomavirus middle $\mathrm{T}$ antigen which retains full and associated phosphatidylinositol kinase activity. J ournal of Virology, 64: 4454-4461.

37. Whitman M, Kaplan DR, Schaffhausen B, Cantley L \& Roberts TM (1985). Association of phosphatidylinositol kinase activity with polyoma middle $T$ competent for transformation. Nature, 315: 239-242.

38. Rameh LE, Chen C-S \& Cantley LC (1995). Phosphatidylinositol $(3,4,5) \mathrm{P} 3$ interacts with $\mathrm{SH} 2$ domains and modulates PI 3kinase association with tyrosine-phosphorylated proteins. Cell, 83: 821-830.

39. Summers SA, Lipfert $L \&$ Bimbaum MJ (1998). Polyoma middle $T$ antigen activates the Ser/Thr kinase Akt in a PI3-kinase-dependent manner. Biochemical and Biophysical Research Communications, 256: 76-81.

40. Dahl J , J urczak A, Cheng LA, Baker DC \& Benjamin TL (1998). Evidence of a role for phosphatidylinositol 3-kinase activation in the blocking of apoptosis by polyomavirus middle T antigen. J ournal of Virology, 72: 3221-3226.

41. Webster MA, Hutchinson J N, Rauh MJ , Muthuswamy SK, Anton M, Tortorice CG, Cardiff RD, Graham FL, Hassel J A \& Miller WJ (1998). Requirement for both Shc and phosphatidylinositol 3' kinase signaling pathways in polymavirus middle T-mediated mammary tumorigenesis. Molecular and Cellular Biology, 18: 2344-2359.

42. Rameh LE \& Armelin MCS (1992). Downregulation of $\mathrm{J}$ and $\mathrm{KC}$ genes by glucocorticoids does not prevent the $\mathrm{G} 0 \rightarrow \mathrm{Gl}$ transition in Balb/3T3 cells. Molecular and Cellular Biology, 12: 4612-4621.

43. Rameh LE \& Armelin MCS (1991). T antigens role in polyomavirus transformation: c-myc but not cFos or c) un expression is a target for middle T. Oncogene, 6: 10491056.

44. Sabapathy KT, Pepper MS, Kiefer F, Mohle-Steinlein $U$, Tacchini-Cottier $F$, Fetka I, Breier G, Risau W, Cameliet P, Montesano R \& Wagner EF (1997). Polyoma middle $\mathrm{T}$-induced vascular tumor formation: the role of the plasminogen activator/plasmin system. J ournal of Cellular Biology, 137: 953-963.

45. Hunter T (1996). Tyrosine phosphorylation: past, present and future. Biochemical Society Transactions, 24: 307-327.

46. Kenedy AP, Sekulic A, I Ivin BJ , Nilson AE, Dilworth SM \& Abraham RT (1998). Polyomavirus middle $T$ antigen as a probe for $T$ cell antigen receptor-coupled signalling pathways. J ournal of Biological Chemistry, 273: 11505-11513. 